\title{
Políticas públicas para acesso de pessoas com deficiência ao ensino superior brasileiro: uma análise de indicadores educacionais
}

\author{
Diléia Aparecida Martins a \\ Lúcia Pereira Leite ${ }^{b}$ \\ Cristina Broglia Feitosa de Lacerda ${ }^{c}$
}

\section{Resumo}

O presente trabalho tem por objetivo analisar as políticas relativas às matrículas da educação especial no ensino superior brasileiro com base em indicadores educacionais. A pesquisa se caracteriza como descritivo-analítica com base documental, cujas fontes de dados foram resumos técnicos e planilhas do Censo da Educação Superior no período de 2000 a 2011 e documentos do Programa Incluir no período de 2005 a 2011, quinquênio em que foi implantado. A escolha pela década em questão justifica-se pelas ações do governo federal previstas no Plano Nacional de Educação direcionadas à ampliação de matrículas no ensino superior brasileiro e pela necessidade de problematizar os resultados dessas ações. A análise dos dados permite identificar a evolução do número de matrículas de estudantes com deficiência em cursos de graduação presencial e a distância - sobretudo em instituições públicas - após a criação do Programa Incluir. De modo geral, o quadro de matrículas de pessoas com deficiência no ensino superior evolui em termos numéricos, mas ainda representa uma camada mínima da população com deficiência efetivamente matriculada nessa etapa da escolarização.

Palavras-chave: Ensino superior. Educação especial. Indicadores educacionais.

a Universidade Federal de São Carlos- UFSCar, Departamento de Psicologia e Curso de bacharelado em tradução e interpretação em Libras/Português - UFSCar, Grupo de Pesquisa Abordagem Bilíngue e Surdez. São Carlos, São Paulo, Brasil.

b Universidade Estadual Paulista - Unesp, Departamento de Psicologia e do Programa de Pós-graduação em Psicologia do Desenvolvimento e Aprendizagem. Bauru, São Paulo, Brasil.

c Universidade Federal de São Carlos- UFSCar, Programa de Pós-Graduação em Educação Especial (PPGEEs). Curso de licenciatura em Educação Especial - UFSCar, Grupo de Pesquisa Abordagem Bilíngue e Surdez. São Carlos, São Paulo, Brasil. 


\section{Introdução}

A análise de políticas relativas às matrículas da educação especial no ensino superior brasileiro torna-se objeto de interesse na atualidade, pois permite identificar dados em meio ao processo histórico da educação da pessoa com deficiência, que foi caracterizada, durante um longo período, por um ensino apartado da educação comum e pública (JANUZZI, 2004).

O presente trabalho se configura como uma pesquisa documental e propõe uma análise relativa ao acesso de estudantes com deficiência ao ensino superior brasileiro, com base em indicadores educacionais de referência nacional. Ainda, procura apresentar uma análise crítica da evolução do ingresso desses estudantes em cursos de graduação - tanto na modalidade presencial como na modalidade de ensino a distância - e as ações governamentais para melhoria das condições de acessibilidade para pessoas com deficiência, permitindo identificar fatores favoráveis, ou não, à ampliação do número de matrículas.

A referida análise reflete as condições materiais impostas à formação humana, sendo a educação escolar uma das principais referências formativas para o alcance aos níveis mais elevados de ensino. Contrapondo-se aos pressupostos da história da Educação Especial, que revela a imposição de barreiras para o acesso à educação básica, documentos governamentais têm apresentado dados quantitativos que denotam a ampliação das matrículas e a melhoria na qualidade da educação.

Nessa perspectiva, indaga-se se as políticas viabilizaram de fato a ampliação do acesso e da permanência de estudantes com deficiência em Instituições de Educação Superior (IES). Para isso, considera-se que o tratamento de indicadores educacionais tem apresentado-se como uma alternativa benéfica para pesquisas no campo da educação (BUENO; MELETTI, 2011), indicando a necessidade de uma leitura ampla do cenário educacional, de modo macroscópico, buscando apontar a influência das ações políticas e econômicas na educação da pessoa com deficiência no país.

\section{Políticas educacionais, educação especial e ensino superior}

A conquista de direitos sociais, refletida pela publicação da Constituição Federal de 1988, realça a noção de universalização do acesso à educação como fator prioritário na definição de políticas públicas, fator este que contribuiu para reformas do sistema educacional brasileiro. 
Ao longo da década de 1990, devido à influência de processos internacionais, o governo brasileiro, sob a égide do neoliberalismo, propôs metas para o desenvolvimento do país. Segundo Gentili (1996), o uso da educação para satisfazer mais diretamente aos interesses empresariais e industriais - a mercantilização da educação - é parte de um projeto hegemônico, característico do neoliberalismo, impondo intensa mudança material e, paralelamente, a reconstrução política e discurso-ideológica da sociedade.

Quanto à influência de processos externos na educação escolar, como propõe Noronha (2002), interesses antagônicos emergiram do processo de expansão do poder em posse da burguesia e se consolidaram em face da crescente tendência em excluir a classe subalterna da participação efetiva na ordem social. No Brasil, o processo de unificação presente em um discurso hegemônico de direito à igualdade, mas que consolida as diferenças de classes e a exploração, pode ser identificado no formato dos serviços disponíveis aos grupos socialmente desfavorecidos. Nesse movimento, se vê na pessoa com deficiência o reflexo desse processo social, no qual o Estado, ao contribuir para a expansão da educação mercantilista, distancia-se cada vez mais de seu compromisso de garantir o direito coletivo.

Na Educação Especial, esse processo é identificado na crescente ascensão das instituições especializadas, financiadas por recursos públicos, mas em posse de pessoas e grupos com interesses individuais. Ao transferir a responsabilidade pela educação da pessoa com deficiência para essas instituições, o governo se eximiu de seu papel retirando desse público o direito ao acesso à educação pública em situação de igualdade com os demais membros da sociedade.

Segundo Kassar (1998), há uma tênue linha entre os papéis dos serviços da Educação Especial de atendimento público e privado. A institucionalização do ensino da pessoa com deficiência tornou nebulosa a atuação do setor público, já que, embora o funcionamento de tais instituições seja financiado pelo poder público - por meio de recursos do Fundo Nacional de Desenvolvimento da Educação (FNDE) -, permite-se que ajam com base em interesses individuais.

A problemática ocasionada por essa realidade configurou uma Educação Especial pela oferta da educação em espaços externos à escola comum. Mazzota (2001) destaca nesse contexto político o compromisso do poder público com a iniciativa privada; o que, em relação ao ensino comum, representa entraves à melhoria da qualidade do ensino na escola pública e a manutenção de práticas assistencialistas por grupos em instituições. Há de se considerar que havia a possibilidade de investir em ambas as modalidades de atendimentos - público e privado - pois 
ambos beneficiariam de alguma maneira a população. No entanto, o poder público transferiu, junto com a dotação orçamentária, o seu compromisso para com esses cidadãos.

Do ponto de vista da gestão da Política Nacional da Educação Especial, o contexto era resultante das modificações impostas ao Centro Nacional de Educação Especial (CENESP), criado pelo Decreto $\mathrm{n}^{\circ} 72.425$, de 1973 (BRASIL, 1973). Mantida a sua competência e estrutura, ele foi transformado na Secretaria de Educação Especial (SESPE), como órgão central de direção superior do Ministério da Educação. A Secretaria de Educação Especial (SESPE) foi extinta no governo de Fernando Collor de Melo (1990-1992), mas retomada no governo Itamar Franco (1992-1994) sob a sigla SEESP e regida por documentos internacionais e leis nacionais que serão a seguir brevemente retomados.

A princípio, dois documentos internacionais precisam ser destacados. A Declaração de educação para todos (UNESCO, 1990), que, em seu texto oficial, afirma que milhões de pessoas deixam de concluir a educação básica. Nessa direção, a revisão de metas e planos para a educação ocorre no sentido de promover a satisfação das necessidades de aprendizagem de crianças em idade escolar, mas que de alguma maneira se encontravam em situação de fracasso, evasão ou analfabetismo. A Declaração de Salamanca (UNESCO, 1994) propôs que a educação de pessoas com deficiência fosse considerada parte integrante do sistema educacional. A Declaração recuperou os apontamentos da Declaração de Direitos Humanos, fazendo com que a Educação Especial fosse vista como parte integrante da política educacional brasileira.

Pela influência de tais documentos, no Brasil, o novo texto da Lei de Diretrizes e Bases para Educação Nacional (BRASIL, 1996a) assegurou o ensino de pessoas com deficiência, retomando elementos presentes na Constituição de 1988, ao reafirmar a necessidade de expandir o acesso desses sujeitos ao ensino comum, propondo que o ensino desse público ocorra prioritariamente na rede regular.

No que tange à educação superior, o Ministério da Educação (MEC) direcionou às IES o aviso circular $\mathrm{n}^{\circ} 277$, em 1996 (BRASIL, 1996b), para que providenciassem adequações no processo seletivo para candidatos com deficiência. O texto dessa circular menciona que, devido ao fato de os levantamentos estatísticos no Brasil não contemplarem naquele período o atendimento educacional disponível às pessoas com deficiência, havia dificuldade na exposição de dados acerca do número desses estudantes concluintes do ensino médio (naquele período chamado $2^{\circ}$ grau) e do número daqueles que ingressavam no ensino superior. Há menção 
ainda ao elevado número de solicitações de pais, estudantes com deficiência e IES requerendo apoio para a viabilização do acesso de candidatos ao ensino superior. Com base na orientação disponibilizada por especialistas, o aviso circular propõe os seguintes ajustes:

Processo de Seleção: - na elaboração do edital, para que possa expressar, com clareza, os recursos que poderão ser utilizados pelo vestibulando no momento da prova, bem como dos critérios de correção a serem adotados pela comissão do vestibular; - no momento dos exames vestibulares, quando serão providenciadas salas especiais para cada tipo de deficiência e a forma adequada de obtenção de respostas pelo vestibulando; - no momento da correção das provas, quando será necessário considerar as diferenças específicas inerentes a cada portador de deficiência, para que o domínio do conhecimento seja aferido por meio de critérios compatíveis com as características especiais desses alunos.

Para o acesso: - instalação de Bancas Especiais contendo, pelo menos, um especialista na área de deficiência do candidato; - utilização de textos ampliados, lupas ou outros recursos ópticos especiais para as pessoas com visão subnormal/reduzida; - utilização de recursos e equipamentos específicos para cegos: provas orais e/ou em Braille, sorobã, máquina de datilografia comum ou Perkins/Braille, DOS VOX adaptado ao computador. - colocação de intérprete no caso de Língua de Sinais no processo de avaliação dos candidatos surdos; - flexibilidade nos critérios de correção da redação e das provas discursivas dos candidatos portadores de deficiência auditiva, dando relevância ao aspecto semântico da mensagem sobre o aspecto formal e/ou adoção de outros mecanismos de avaliação da sua linguagem em substituição à prova de redação. - adaptação de espaços físicos, mobiliário e equipamentos para candidatos portadores de deficiência física; - utilização de provas orais ou uso de computadores e outros equipamentos pelo portador de deficiência física com comprometimento dos membros superiores; - ampliação do tempo determinado para a execução das provas de acordo com o grau de comprometimento do candidato; - criação de um mecanismo que identifique a deficiência da qual o candidato é portador, de forma que a comissão do vestibular possa adotar critérios de avaliação compatíveis com as características inerentes a essas pessoas (BRASIL, 1996b). 
O governo sugere, por meio desse documento, que as IES organizem ações para a flexibilização dos serviços educacionais, infraestrutura e capacitação de recursos humanos para atendimento das necessidades especiais de pessoas com deficiência. Em complemento, pela Lei $n^{\circ} 10.098$, de 2000 (BRASIL, 2000), compreende-se que acessibilidade é a possibilidade e a condição de alcance para utilização com segurança e autonomia dos espaços, mobiliários e equipamentos, das edificações e dos sistemas e meios de comunicação. As condições de acessibilidade para pessoas com deficiência estão associadas ainda às definições de barreiras presentes na mesma lei:

II - barreiras: qualquer entrave ou obstáculo que limite ou impeça o acesso, a liberdade de movimento e a circulação com segurança das pessoas, classificadas em: a) barreiras arquitetônicas urbanísticas: as existentes nas vias públicas e nos espaços de uso público; b) barreiras arquitetônicas na edificação: as existentes no interior dos edifícios públicos e privados; c) barreiras arquitetônicas nos transportes: as existentes nos meios de transportes; d) barreiras nas comunicações: qualquer entrave ou obstáculo que dificulte ou impossibilite a expressão ou o recebimento de mensagens por intermédio dos meios ou sistemas de comunicação, sejam ou não de massa (BRASIL, 2000, p. 1).

Essa noção de acessibilidade para pessoas com deficiência vem desde então compondo os programas educacionais e ganhando destaque no plano de governo de representantes políticos. Todavia, para efeito da análise aqui proposta, destaca-se o período de reformas realizadas no Brasil na gestão do Partido dos Trabalhadores presidentes Luis Inácio Lula da Silva e Dilma Housseff (2003/2010 e 2011/2013) e, para isso, se faz necessária a apresentação do cenário político que o antecedeu.

Durante o governo de Fernando Henrique Cardoso (FHC) (1995-2003), foram determinadas novas formas de financiamento, gestão e avaliação da educação, com uma nova forma de regulação assentada na descentralização e na flexibilidade - chamadas de autonomia local. No início dos anos 2000, o Conselho Nacional de Educação (CNE) promulgou a resolução que instituiu as Diretrizes Nacionais para a Educação Especial na Educação Básica (BRASIL, 2001a), documento que, com caráter de lei, regula os artigos da Lei de Diretrizes e Bases da Educação (LDBEN) - n 9.394/1996 (BRASIL, 1996a). A mesma instituía a Educação Especial como modalidade de ensino e o atendimento educacional especializado aos alunos com necessidades especiais na rede pública desde a educação infantil até o ensino superior. 
Ao longo da década 2000-2010, eventos internacionais influenciaram a educação brasileira, tais como a Convenção de Guatemala (2001) e a Convenção de Nova York (2006). A primeira, Convenção interamericana para a eliminação de todas as formas de discriminação contra as pessoas portadoras de deficiência, foi realizada na Guatemala em 2001 e aprovada no Brasil pelo Decreto $n^{\circ} 198$ do mesmo ano (BRASIL, 2001@A segunda, Convenção sobre os direitos das pessoas com deficiência, foi assinada em Nova York em 30 de março de 2007 e aprovada no Brasil pelo Decreto legislativo no 186/2008 (BRASIL, 2008a). Ambas introduziram a urgência na adoção e no fomento a projetos para popularização do direito da pessoa com deficiência para que a sociedade brasileira pudesse capacitar-se para repulsa a atos discriminatórios.

No que se refere especificamente à educação, a resolução $\mathrm{CNE} / \mathrm{CEB} \mathrm{n}^{\circ} 2$, de 2001, que institui Diretrizes Nacionais para a Educação Especial na Educação Básica, propalou ainda que:

Art. $7^{\circ}$. O atendimento aos alunos com necessidades educacionais especiais deve ser realizado em classes comuns do ensino regular, em qualquer etapa ou modalidade da Educação Básica.

Art. $8^{\circ}$ As escolas da rede regular de ensino devem prever e prover na organização de suas classes comuns: I - professores das classes comuns e da educação especial capacitados e especializados, respectivamente, para o atendimento às necessidades educacionais dos alunos; II - distribuição dos alunos com necessidades educacionais especiais pelas várias classes do ano escolar em que forem classificados, de modo que essas classes comuns se beneficiem das diferenças e ampliem positivamente as experiências de todos os alunos, dentro do princípio de educar para a diversidade; III - flexibilizações e adaptações curriculares que considerem o significado prático e instrumental dos conteúdos básicos, metodologias de ensino e recursos didáticos diferenciados e processos de avaliação adequados ao desenvolvimento dos alunos que apresentam necessidades educacionais especiais, em consonância com o projeto pedagógico da escola, respeitada a frequência obrigatória [...] (BRASIL, 2001a, p. 2).

Por meio da leitura dessas orientações, foi possível compor um norte para as ações municipais e estaduais na organização de um trabalho pedagógico capaz de tornar o ensino comum acessível ao estudante com deficiência. Como se pode 
observar, embora seja explicitada a noção de que a Educação Especial se constitui como uma modalidade de educação escolar que se inicia na educação infantil, o texto das diretrizes e leis tem por foco a oferta da educação básica.

Após a retomada de aspectos que interferiram na configuração da Educação Especial nesse período histórico, pode-se aferir que a Educação Especial se instituiu em espaços e locais para funcionamento de serviços considerando os termos da legislação: a) A existência do Atendimento Educacional Especializado para pessoas com deficiência preferencialmente na rede regular de ensino; b) A Educação Especial como modalidade de educação escolar oferecida preferencialmente na rede regular de ensino; c) A oferta de serviços de apoio especializado no ensino público para atender peculiaridades da clientela da educação especial; d) A oferta da educação especial como um dever constitucional com início na educação infantil.

\subsection{A democratização do ensino superior brasileiro}

Contextualizando a configuração da educação especial no período histórico relativo aos dados da presente pesquisa, o início do governo Lula 2003-2010, segundo Singer (2012), partiu de um grau elevado de miséria e desigualdade, em meio a uma conjuntura econômica mundial favorável entre 2003 e 2008, que apresentava um ciclo de expansão capitalista. As decisões do primeiro mandato de Lula revelaram sua opção por uma estratégia política que compartilhava da onda de expansão mundial, mas em um caminho intermediário ao neoliberalismo da década anterior. Para Oliveira (2009), os programas sociais implementados pelo governo Lula, em seu primeiro mandato, eram assistenciais e compensatórios. Para o investimento na população de baixa renda, nos mais pobres e miseráveis abaixo da linha da pobreza, estimulou ações que em alguma medida impactavam no campo da educação.

Ao longo de seu governo foram implementados os programas sociais: Bolsa Família; Fome Zero; Primeiro Emprego; combate à mortalidade infantil e à escravidão, sendo que a maior parte possuía um envolvimento direto com a educação. A exemplo, o Bolsa Família, criado por meio do Decreto n ${ }^{\circ} 5.209$, de 2004 (BRASIL, 2004a), tinha por finalidade transferir renda direta do governo para as famílias em situação de extrema miséria, e uma das exigências principais, sob pena de perda da bolsa, era que todos os membros da família em idade escolar deveriam frequentar a escola. Tratava-se da ampliação e reformulação do programa Bolsa Escola criado no governo de FHC. Amostras coletadas pelo Instituto Brasileiro de Geografia e Estatística (IBGE) quando da realização do recenseamento populacional vêm demonstrando que tais programas e políticas 
alteraram as condições de vida de seus beneficiados, melhorando sua renda e possibilitando a ampliação do acesso a produtos e a serviços (IBGE, 2012).

Singer (2012) constata em seu estudo que, após a implantação de programas sociais, as intenções de voto da população mais pobre ampliaram-se significativamente em benefício do Partido dos Trabalhadores, resultando na segunda vitória do presidente e em seguida na continuidade do projeto petista, tendo Dilma Roussef como chefe do Poder Executivo. A questão está em compreender o quanto as ações deste governo tiveram como meta a reversão dos índices de pobreza e a melhoria da qualidade da educação, a superação de barreiras de pessoas com deficiência e outros grupos desfavorecidos socialmente ou se sua meta esteve na busca de votos e interesses políticos individuais. Considera-se aqui que a mera busca pela manutenção de interesses individuais representaria à nossa sociedade a continuidade do processo de investimento em ações paliativas, que não atuam efetivamente sobre os problemas da educação pública.

Para garantir que as mudanças fossem de fato efetivas, seria necessário propor um projeto político comprometido com a superação das desigualdades sociais. No intuito de melhor conhecer as intenções dos atos políticos, observa-se que o projeto de governo petista reconheceu a Educação Especial como uma modalidade de ensino para a qual a alocação de recursos e financiamento específicos seriam indispensáveis, e exigiu a criação de condições para acesso e permanência de estudantes com deficiência na escola comum. Dentre as propostas de governo pode-se destacar:

Garantir a acessibilidade, provendo: - transporte escolar; edificações que permitam o acesso ao cadeirante; - estímulos e pistas visuais para os deficientes sensoriais, com comunicação e sinalização adequadas; - atendimento em sala de aula regular, com acompanhamento de equipe especializada; - capacitação continuada dos professores que farão o acompanhamento desses alunos; - atendimento em sala de recursos, em horários especiais, quando a sala regular mostrar-se insuficiente; - equipes técnicas volantes para assessoria aos professores das salas de recursos; - atendimento em salas de educação especial, na escola regular, quando a condição de aprendizado tornar-se inadequada em salas regulares; - atendimento em escolas especiais, para os alunos que não se beneficiem das modalidades anteriores, com equipe de apoio e professores especializados (CADERNO temático..., 2002, p 10). 
A proposta de governo de Lula, então candidato à presidência, já de berço, contemplava uma atenção diferenciada à Educação Especial. Seria esse um diferencial em comparação aos demais governantes? No governo anterior, conforme assumido por Paulo Renato de Souza no aviso circular no 277 (BRASIL, 1996b), não havia sequer o acompanhamento estatístico de dados referentes ao número de estudantes com deficiência matriculados e concluintes da educação básica, muito menos dos candidatos e matriculados na educação superior; indicando desinteresse por este tema e/ou que não se problematizava a adoção de uma proposta educacional institucionalizada em detrimento de ações para transformação da escola comum e da educação pública.

No ano de 2006, foi publicado o documento Números da Educação Especial no Brasil, que contempla um diagnóstico quantitativo da Educação Especial no país. O documento indica que houve aumento do número de estudantes com deficiência matriculados na escola comum pública entre os anos 1998 e 2006. Menciona que nesse período houve crescimento de $640 \%$ das matrículas em escolas comuns (o que se nomeia de inclusão) e de $28 \%$ em escolas e classes especiais (BRASIL, 2006a).

Segundo esse mesmo documento, com relação às condições de infraestrutura nas escolas públicas; um ano antes da posse do presidente Lula, em 2002, havia 5.016 escolas públicas com sanitários adequados aos "alunos com necessidades educacionais especiais" e 3.755 escolas públicas com dependências e vias adequadas aos alunos com necessidades educacionais especiais. Em 2006, os números eram 12.684 e 8.888 respectivamente. Na educação superior, no ano de 2003, início do primeiro mandato petista, havia um total de 5.078 matrículas de estudantes com deficiência em IES, sendo 1.373 em IES públicas e 3.705 em IES privadas.

A proposta de governo que assumia o desafio de construir um sistema educacional inclusivo no país contemplava a adoção de ações voltadas para a inclusão escolar dos estudantes com deficiência, transtornos globais de desenvolvimento e altas habilidades. De acordo com a síntese do balanço elaborado pelo governo federal ${ }^{1}$, segundo discurso do próprio ex-presidente Lula, o objetivo foi

comparar o meu programa de governo, os compromissos que assumi, com as coisas que eu realizei [...]. Eu quero entregar ao meu sucessor, à imprensa, aos sindicalistas, às entidades empresariais [...] cada coisa que nós fizemos, cada obra, cada projeto, cada investimento, que é para não apagar a memória (BRASIL, 2013, p. 139).

\footnotetext{
${ }^{1} \mathrm{O}$ balanço completo pode ser acessado pelo site: http://www.balancodegoverno.presidencia.gov.br/.
} 
Compõe esse balanço um destaque do governo federal à criação, em 2003, do Programa Educação Inclusiva: Direito à diversidade ${ }^{2}$, que fomentou a abertura de debate resultante na elaboração da nova Política da Educação Especial. Por esse Programa foram apresentados os conceitos utilizados no censo escolar referentes às tipologias de deficiência. Lançada em 2008, a Política da Educação Especial na perspectiva da educação inclusiva (BRASIL, 2008c) ${ }^{3}$ retomou todo processo histórico da educação da pessoa com deficiência com base nos acordos internacionais e em leis nacionais e destacou o objetivo

de promover o acesso, a participação e a aprendizagem dos alunos com deficiência, transtornos globais do desenvolvimento e altas habilidades/superdotação nas escolas regulares, orientando os sistemas de ensino para promover respostas às necessidades educacionais especiais, garantindo: Transversalidade da educação especial desde a educação infantil até a educação superior; Atendimento educacional especializado; Continuidade da escolarização nos níveis mais elevados do ensino; Formação de professores para o atendimento educacional especializado e demais profissionais da educação para a inclusão escolar; Participação da família e da comunidade; Acessibilidade urbanística, arquitetônica, nos mobiliários e equipamentos, nos transportes, na comunicação e informação e Articulação intersetorial na implementação das políticas públicas (BRASIL, 2008c, p. 8).

Define o público-alvo da Educação Especial:

Considera-se pessoa com deficiência aquela que tem impedimentos de longo prazo, de natureza física, mental ou sensorial que, em interação com diversas barreiras, podem ter restringida sua participação plena e efetiva na escola e na sociedade. Os alunos com transtornos globais do desenvolvimento são aqueles que apresentam alterações qualitativas das interações sociais recíprocas e na comunicação, um repertório de interesses e atividades restrito, estereotipado e repetitivo. Incluem-se nesse grupo alunos com

\footnotetext{
O Ministério da Educação, por meio da Secretaria de Educação Especial, desenvolve o Programa Educação Inclusiva: Direito à diversidade em todos os estados e Distrito Federal, envolvendo 106 municípios-pólo que atuam como multiplicadores para municípios da sua área de abrangência, compreendendo atualmente 1.869 municípios. O objetivo é a formação de gestores e educadores para efetivar a transformação dos sistemas educacionais em sistemas educacionais inclusivos, tendo como princípio a garantia do direito dos alunos com necessidades educacionais especiais de acesso e permanência, com qualidade, nas escolas regulares.

3 O documento oficial foi elaborado pelo Grupo de Trabalho nomeado pela Portaria Ministerial n 555 , de 5 de junho de 2007, prorrogada pela Portaria n 948, de 9 de outubro de 2007.
} 
autismo, síndromes do espectro do autismo e psicose infantil. Alunos com altas habilidades/superdotação demonstram potencial elevado em qualquer uma das seguintes áreas, isoladas ou combinadas: intelectual, acadêmica, liderança, psicomotricidade e artes, além de apresentar grande criatividade, envolvimento na aprendizagem e realização de tarefas em áreas de seu interesse (BRASIL, 2008c, p. 9).

Neste artigo, o foco está no estudante com deficiência em concordância com a Resolução CNE/CEB n 4/2009, inciso I - "Alunos com deficiência: aqueles que têm impedimentos de longo prazo de natureza física, intelectual, mental ou sensorial". Já segundo o Decreto $\mathrm{n}^{\circ} 5296 / 04$, que regulamenta as leis $\mathrm{n}^{\circ} 10.048 \mathrm{e}$ $\mathrm{n}^{\circ} 10.098 / 2000$, art. $5^{\circ}$, parágrafo $1^{\circ}$, "Considera-se, para os efeitos deste Decreto: I - pessoa portadora de deficiência, além daquelas previstas na Lei $\mathrm{n}^{\circ} 10.690$, de 16 de junho de 2003, a que possui limitação ou incapacidade para o desempenho de atividade e se enquadra nas seguintes categorias":

a) deficiência física: alteração completa ou parcial de um ou mais segmentos do corpo humano, acarretando o comprometimento da função física, apresentando-se sob a forma de paraplegia, paraparesia, monoplegia, monoparesia, tetraplegia, tetraparesia, triplegia, triparesia, hemiplegia, hemiparesia, ostomia, amputação ou ausência de membro, paralisia cerebral, nanismo, membros com deformidade congênita ou adquirida, exceto as deformidades estéticas e as que não produzam dificuldades para o desempenho de funções;

b) deficiência auditiva: perda bilateral, parcial ou total, de quarenta e um decibéis $(\mathrm{dB})$ ou mais, aferida por audiograma nas frequências de $500 \mathrm{~Hz}, 1.000 \mathrm{~Hz}, 2.000 \mathrm{~Hz}$ e $3.000 \mathrm{~Hz}$;

c) deficiência visual: cegueira, na qual a acuidade visual é igual ou menor que 0,05 no melhor olho, com a melhor correção óptica; a baixa visão, que significa acuidade visual entre 0,3 e 0,05 no melhor olho, com a melhor correção óptica; os casos nos quais a somatória da medida do campo visual em ambos os olhos for igual ou menor que 60; ou a ocorrência simultânea de quaisquer das condições anteriores (BRASIL, 2004b).

Ressalta-se ainda que os dados foram obtidos a partir da consulta aos indicadores educacionais e aos dados disponibilizados pelo INEP e, portanto, essa identificação da pessoa portadora de deficiência esteve sob custódia desse órgão e não dos pesquisadores. 
Mediante esse público-alvo, retomando a Política de Educação Especial (BRASIL, 2008c), para a educação superior, devem ser efetivadas ações que promovam o acesso, a permanência e a participação dos estudantes com deficiência, envolvendo o planejamento e a organização de recursos e serviços para a promoção da acessibilidade arquitetônica, nas comunicações, nos sistemas de informação, nos materiais didáticos e pedagógicos, que devem ser disponibilizados nos processos seletivos e no desenvolvimento de todas as atividades que envolvam o ensino, a pesquisa e a extensão.

Por meio do Decreto $\mathrm{n}^{\circ}$ 6.571/2008 (BRASIL, 2008b), que dispôs sobre o Atendimento Educacional Especializado (AEE), foi instituído no âmbito do Fundo do Desenvolvimento da Educação Básica (Fundeb), o financiamento do AEE e o trabalho desempenhado pela Educação Especial passou a centralizar-se em recursos e serviços: "conjunto de atividades, recursos de acessibilidade e pedagógicos organizados institucionalmente, prestados de forma complementar ou suplementar à formação dos alunos no ensino regular" (BRASIL, 2008b, p. 1). Nessa linha de trabalho, o Programa Escola Acessível e Sala de Recursos Multifuncionais promoveram a adaptação e adequação de prédios e salas escolares para atender pessoas com deficiência e mobilidade reduzida, disponibilizando um conjunto de mobiliário adequado aos alunos público-alvo da Educação Especial (BRASIL, 2008c). Entre 2008 e 2009, 11.205 escolas implementaram ações de acessibilidade. Em 2011, o Decreto $n^{\circ} 6.571 / 2008$ foi substituído pelo Decreto $\mathrm{n}^{0} 7.611$ (BRASIL, 2011a).

Em complemento, a resolução CNE/CEB n ${ }^{\circ} 4 / 2009$, que instituiu as Diretrizes operacionais para o AEE na educação básica (BRASIL, 2009), apresenta como lócus do AEE a Sala de Recursos Multifuncionais (SRM). Desse modo, a Educação Especial passa a caracterizar-se pelo trabalho realizado na escola comum sob a perspectiva inclusiva. Em face desse modo característico de funcionamento da Educação Especial - tendo por base a frequência do aluno à escola comum e no contraturno escolar à SRM -, indaga-se quanto e como esse atendimento contemplaria de fato as necessidades dos estudantes.

Após a publicação de leis e decretos que modificaram fundamentalmente a oferta dos serviços de Educação Especial, através de notas técnicas e pareceres, o Ministério da Educação disponibilizou orientações aos sistemas de ensino quanto ao uso de recursos. No que se refere à acessibilidade, a então Secretaria de Educação Continuada, Alfabetização, Diversidade e Inclusão (Secadi) articulou, por meio de seus gestores, o pareamento de dados dos Programas Dinheiro Direto na Escola, Implantação da Educação Bilíngue, Publicação em formato acessível, 
Avaliação do estudante com deficiência intelectual entre outros, visando o uso de recursos e repasses governamentais para a manutenção do AEE na escola pública. Um destaque deve ser feito ao reduzido foco nas instituições especializadas, cujo repasse da verba vem sendo avaliado constantemente, uma vez que o foco está na matrícula do estudante com deficiência na escola comum.

A proposta do governo vigente nesse período poderia ser considerada eficaz? No período, diversas modificações foram propostas. No entanto, segundo Garcia e Michels (2011), ao longo do governo de Luís Inácio Lula da Silva, a Política Nacional de Educação Especial ganhou novos contornos, de modo singular, pela implementação de três programas: 1) Programa de Implantação de Salas de Recursos Multifuncionais; 2) Programa Educação Inclusiva: direito à diversidade e 3) Programa Incluir. O primeiro, por representar o fortalecimento do processo de inclusão de estudantes com deficiência na escola comum de ensino regular pública. $\mathrm{O}$ segundo, por fomentar entre os gestores estaduais e municipais as metas assumidas pelo governo dentro do projeto de educação para todos. Há nesse programa a intenção de expandir as ações do Atendimento Educacional Especializado. Pelo programa de implementação de Salas de Recursos Multifuncionais e pelo Decreto $\mathrm{n}^{\circ}$ 6.571/2008 (BRASIL, 2008b), o lócus privilegiado do AEE continua sendo a complementação e suplementação à educação regular. Tais programas representam atos concretos da gestão política governamental que resultaram na modificação direta do cenário da Educação Especial no país, na educação básica.

No que tange à educação superior, o terceiro programa, o Incluir, propõe ações que visam o acesso de pessoas com deficiência às instituições federais. Se na educação básica era possível identificar com clareza as opções disponíveis para estudantes com deficiência, na educação superior, somente em 2000, a extinta Secretaria de Educação Especial (SEESP/MEC) e a Secretaria de Ensino Superior (SESU/MEC) direcionaram às IES orientações específicas para adaptação dos recursos instrucionais, capacitação de recursos humanos e adequação de recursos físicos, indicando que cada IES apresente um plano de implantação da acessibilidade, de modo a favorecer o acesso, o ingresso e a permanência desses estudantes com deficiência no ensino superior. Em 2003, foi publicada a Portaria $\mathrm{n}^{\circ} 3.284$ (BRASIL, 2003), que estabelece normas para oferta de cursos superiores, reafirmando o compromisso formal das IES para com os estudantes com deficiência.

Somente em 2005, as universidades federais foram dotadas dos recursos do Incluir (BRASIL, 2005). O Incluir, desde sua criação, é executado por meio da parceria 
entre a SESu e a Secretaria de Educação Continuada, Alfabetização, Diversidade e Inclusão (Secadi), ambas do Ministério de Educação. Essas secretarias divulgavam um edital público com dotação orçamentaria - induzindo as universidades a executarem ações que tivessem como foco o público-alvo da Educação Especial.

Pelo intermédio do auxílio prestado pelo Programa Incluir, as IFES podiam então criar e consolidar núcleos de acessibilidade. Estes, por sua vez, ficavam responsáveis pela organização de ações institucionais para fomentar a inclusão de pessoas com deficiência, propiciar a eliminação de barreiras pedagógicas, arquitetônicas, comunicacionais e de informação, com vistas ao cumprimento dos requisitos legais relacionadas à acessibilidade.

O programa, até 2010, disponibilizava recursos a partir da inscrição das universidades nos específicos editais, sendo selecionadas algumas proposições a serem beneficiadas com repasses financeiros. Em 2012, a seleção deixou de ocorrer, sendo então disponibilizada dotação orçamentária para cada universidade federal que já tivesse sido contemplada, com projeto aprovado, nos anos anteriores. Em 2013 foram alocados recursos diretamente para as Unidades Orçamentárias (UO) de 55 universidades federais.

Quanto à promoção da acessibilidade nos exames nacionais, a Nota Técnica $\mathrm{n}^{\circ} 08 / 2011$ propõe que seja assegurado o direito do estudante com deficiência desde o edital e do formulário de inscrição no exame, que devem informar quanto ao recurso de acessibilidade necessário para sua plena participação.

Após esse estudo acerca de questões relativas às políticas, educação especial e ensino superior, pode-se aludir à demanda investigativa do presente trabalho.

\section{0 ensino superior brasileiro e o acesso de pessoas com deficiência}

A presente pesquisa foi realizada com base na análise do Resumo Técnico do Censo da Educação Superior, no período de publicação entre os anos 2000 e 2011. Esse processo propiciou uma visão geral sobre os documentos referentes à educação superior brasileira publicados pelo Instituto Nacional de Estudos e Pesquisas Educacionais (Inep) e disponibilizados no site oficial da instituição ${ }^{4}$.

${ }^{4}$ INSTITUTO NACIONAL DE ESTUDOS E PESQUISAS EDUCACIONAIS ANÍSIO TEIXEIRA - INEP. Informações estatísticas: indicadores educacionais. Brasília, DF, 2012. Disponível em: <http://portal.inep.gov.br/ indicadores-educacionais >. Acesso em: 10 ago.2012. 
Embora alguns documentos estejam indisponíveis, foi possível consultar nove resumos técnicos, entre os quais seis não dispunham de informações sobre pessoas com deficiência. Pode-se observar o descrito no Quadro 1:

Quadro 1. Análise inicial do Resumo Técnico do Censo da Educação Superior.

\begin{tabular}{|l|c|}
\hline Ano de publicação & Menção à pessoa com deficiência/disponibilidade \\
\hline 2000 & Indisponível \\
\hline 2001 & Indisponível \\
\hline 2002 & Nada consta \\
\hline 2003 & Nada consta \\
\hline 2004 & Nada consta \\
\hline 2005 & Nada consta \\
\hline 2006 & Indisponível \\
\hline 2007 & Nada consta \\
\hline 2008 & Nada consta \\
\hline 2009 & Informações parciais \\
\hline 2010 & Informações parciais \\
\hline 2011 & Informações completas \\
\hline
\end{tabular}

Fonte: INEP/Secretaria da Educação Superior.

Elaborado em março/2014.

Tais documentos revelaram dados sobre o crescimento do número de matrículas em IES por curso, além de pautarem a ampliação de matrículas e a oferta da educação superior em instituições particulares e filantrópicas, destacando os cursos que apresentaram maior número de matrículas.

O levantamento e identificação da distribuição de matrículas e informações referentes à educação superior brasileira, com base em dados coletados nos resumos técnicos e em planilhas do Inep, foram sistematizados na Tabela 1. Os dados numéricos foram agrupados e apresentados de maneira que permitam a leitura da quantidade de matrículas de pessoas com deficiência e as que não se encontram nessa condição na educação superior, pública e privada.

Com a intenção de traçar um panorama das matrículas de pessoas com deficiência no ensino superior público e privado nos últimos dez anos e compreender como o conceito de deficiência foi mencionado, foi realizada a análise dos dados quantitativos. Entretanto, percebeu-se que a apresentação dos documentos 
analisados não seguiu um padrão regular, dispondo as informações de maneira diversa em cada versão/ano, alterando a forma de se referenciar às pessoas com deficiência, por exemplo. Essa inconstância prejudicou a análise dos documentos, inviabilizando o acompanhamento de características comuns ao longo do período pesquisado. Devido a essa variação na disposição dos dados, a análise foi realizada anualmente, sendo então contempladas para o desenvolvimento da pesquisa informações referentes ao número do total de matrículas em IES, a diferenciação público/privado e matrícula de pessoas com deficiência. O Resumo Técnico do Censo da Educação Superior propala:

No ano de 2003, foram oferecidas 2.002.733 vagas nos diversos processos seletivos para graduação presencial. No exame vestibular foram disponibilizadas 1.822.244 vagas, e todos os outros processos seletivos (avaliação seriada no Ensino Médio, Vestibular, Exame Nacional do Ensino Médio - ENEM e outros tipos mais específicos de seleção) contribuíram com 180.489 vagas. Percebe-se, portanto, que o vestibular, não obstante a crescente participação de outros processos, mantém-se como a principal forma de seleção e acesso à educação superior. Quando são consideradas outras formas de ingresso, tais como mudança de curso dentro da IES, transferência ex-officio, transferência vinda de outra IES excluída a ex-officio, acordos internacionais, admissão de diplomados em curso superior, reabertura de matrícula e outros tipos de ingresso, observa-se que ingressaram mais 277.477 estudantes na educação superior, sendo que 222.869 (80,3\%) em IES privadas e 54.608 (19,7\%) em públicas (INEP, 2003).

A citação acima propicia a reflexão acerca da influência da forma de ingresso na IES como um dos principais indicadores de vagas e evolução de matrículas. A principal forma de ingresso foi o exame vestibular, mas a princípio tem-se a impressão de que não foram publicados dados relativos à pessoa com deficiência por não terem sido coletados ou devido à ausência de estudantes com deficiência em IES. No entanto, no mesmo site foi possível localizar uma tabela de dados mais detalhada, contendo uma quantidade considerável de dados referentes às pessoas com deficiência matriculadas em IES.

Ao longo das últimas décadas, tem se fortalecido a concepção de que a educação da pessoa com deficiência deve ocorrer na escola comum, sendo a participação desses educandos efetiva; uma superação das propostas anteriores de institucionalização e integração da pessoa com deficiência. No entanto, as experiências educacionais inclusivas revelam o quanto as implicações da deficiência acarretam modificações 
no processo de escolarização, mediante a existência de um modelo curricular e de uma legislação que fundamenta o funcionamento da instituição escolar. O modo de conceber a deficiência é um fator predominante no sucesso do estudante com deficiência em sua trajetória escolar.

Em determinados momentos, na atualidade, a deficiência é vista como uma limitação ao cumprimento das metas curriculares; em outros momentos, é mascarada pelas noções de igualdade ou de normalização das diferenças. Para além desse modo de compreender a deficiência, a anulação do fator biológico tem por consequência o esquecimento das necessidades de adequação do currículo escolar para atendimento as peculiaridades de cada tipo de deficiência.

A negação da deficiência representa a rejeição do sujeito em sua individualidade. Se por um longo período a pessoa com deficiência sofreu com os estigmas criados pela sua estética corporal ou aparentes inabilidades cognitivas, ainda há muito que lutar para combater o ofuscamento de suas características individuais.

Pela presença e participação limitada da pessoa com deficiência no ambiente escolar, a escola cumpriria de modo extremamente restrito seu papel. Por assim dizer, a noção de que basta inserir o estudante com deficiência não pode ser defendida, muito menos amparada do ponto de vista legal. Se a intenção desse modelo educacional inclusivo é favorecer a plena participação da pessoa com deficiência na escola comum, esta deve prover de meios e recursos capazes de corresponder a essa função primordial da educação escolar.

Essa dimensão de inclusão educacional permite uma possível interpretação desse silêncio no que tange à pessoa com deficiência e sua incorporação em dados estatísticos no documento oficial. A planilha que contém dados numéricos elaborada pelo Inep expõe de modo claro a existência de estudantes com deficiência nas IES naquele período, embora não haja menção a esse público nos resumos técnicos. Uma possível leitura desse fato é de que, no início do governo Lula, embora estivesse presente em sua proposta de governo a atenção diferenciada à Educação Especial, ainda predomina uma concepção de integração da pessoa com deficiência, quando os poucos que chegam aos degraus mais elevados da escolarização são submetidos a um sistema que não identifica sua deficiência e peculiaridades. Por essa razão, tais dados, num primeiro momento, não compuseram as estatísticas educacionais.

Na Tabela 1 - Matrículas em IES: graduação presencial e a distância, estão presentes os dados coletados conforme mencionado anteriormente. 
Tabela 1. Matrículas em IES: graduação presencial e a distância.

\begin{tabular}{cccccccccc}
\hline Ano & Total & $\begin{array}{c}\text { PcD FA } \\
\text { (n) }\end{array}$ & $\begin{array}{c}\text { PcD FR } \\
\text { (\%) }\end{array}$ & $\begin{array}{c}\text { IES } \\
\text { Pública }\end{array}$ & $\begin{array}{c}\text { PcD } \\
\text { FA (n) }\end{array}$ & $\begin{array}{c}\text { PCD } \\
\text { FR) }\end{array}$ & $\begin{array}{c}\text { IES } \\
\text { Privada }\end{array}$ & $\begin{array}{c}\text { PcD FA } \\
\text { (n) }\end{array}$ & $\begin{array}{c}\text { PcD FR } \\
\text { (\%) }\end{array}$ \\
\hline 2000 & 2.694 .245 & 2.173 & 0,08 & 887.026 & 1.135 & 0,13 & 1.807 .219 & 1.038 & 0,06 \\
2001 & 3.030 .744 & 2.898 & 0,10 & 939.225 & 391 & 0,04 & 2.091 .529 & 2.507 & 0,12 \\
2002 & 3.479 .913 & 2.425 & 0,07 & 1.051 .655 & 705 & 0,07 & 2.428 .258 & 1.720 & 0,07 \\
2003 & 3.564 .628 & 5.078 & 0,14 & 1.136 .370 & 1.373 & 0,12 & 2.750 .652 & 3.705 & 0,13 \\
2004 & 4.163 .733 & 5.395 & 0,13 & 1.178 .328 & 1.318 & 0,11 & 2.985 .405 & 4.077 & 0,14 \\
2005 & 4.453 .156 & 6.327 & 0,14 & 1.192 .189 & 2.080 & 0,17 & 3.260 .967 & 4.247 & 0,13 \\
2006 & 4.676 .646 & 6.960 & 0,15 & 1.209 .304 & 1.855 & 0,15 & 3.467 .342 & 5.105 & 0,15 \\
2007 & 4.880 .381 & 6.934 & 0,14 & 1.240 .968 & 1.390 & 0,11 & 3.639 .413 & 5.544 & 0,15 \\
2008 & 5.080 .056 & 12.015 & 0,24 & 1.273 .965 & 1.984 & 0,16 & 3.806 .091 & 10.031 & 0,26 \\
2009 & 5.954 .021 & 20.965 & 0,35 & 1.523 .864 & 6.598 & 0,43 & 4.430 .157 & 14.367 & 0,32 \\
2010 & 6.379 .299 & 20.287 & 0,32 & 1.643 .298 & 6.884 & 0,42 & 4.736 .001 & 13.403 & 0,28 \\
2011 & 6.739 .689 & 23.250 & 0,34 & 1.773 .315 & 6.531 & 0,37 & 4.966 .374 & 16.719 & 0,34 \\
Total & 55.096 .511 & 114.707 & 0,21 & 15.049 .507 & 32.244 & 0,21 & 40.369 .408 & 82.463 & 0,20 \\
\hline
\end{tabular}

PCD: pessoa com deficiência; FA: frequência absoluta; FR: frequência relativa.

Fonte: MEC/INEP.

Elaborado em março/2014.

Pela análise dos dados demonstrados na Tabela 1, percebe-se que ao longo do período analisado houve aumento do número de matrículas de pessoas com deficiência em IES, a exemplo, no ano 2000, quando as matrículas de pessoas com deficiência representavam 0,08 do total geral (total geral 2694245, PcD Fa (n) 2173, PcD FR (\%) 0.08) e, no ano seguinte, foi de 0,10 (total geral 3030744, PcD FA (n) 2898, PcD FR (\%) 0.10). No entanto, nem sequer 1\% da população matriculada em cursos de graduação possuía algum tipo de deficiência.

No que tange ao quantitativo de matrículas por setor público e privado, nota-se um possível comportamento do grupo, alterações que ocorrem ano a ano e que ao longo de uma década podem ser analisados como o foco na tendência de progressão. É o que se pretende apresentar na Figura 1.

Os dados acima apresentados permitem inferir que:

1. Há indícios de que, ao longo dos anos, os estudantes com deficiência estejam chegando em maior número, talvez com maior facilidade, ao ensino superior brasileiro; 


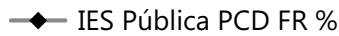

$\square$ - IES Privada PCD FR \%

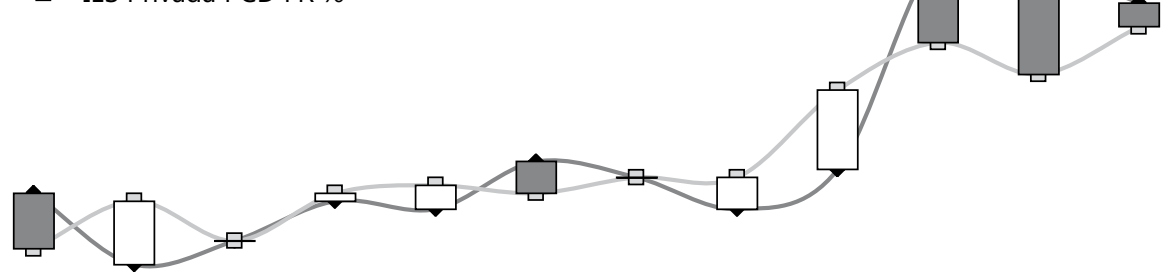

Fonte: Elaborado em março de 2014 pelas autoras com dados coletados pelo INEP referentes ao período de 2000-2011 referentes à matrícula de pessoas com deficiência.

Figura 1. Variação da frequência relativa - Pessoas com Deficiência em IES públicas e privadas (2000 a 2011).

2. Nota-se que a quantidade de estudantes matriculados por setor público e privado caminha em proporção semelhante até o ano 2007, quando há em 2008 uma diferença de 0.10 entre o número de matrículas em IES públicas e privadas, seguido em 2009 da reversão desse dado, quando o número de matrículas em IES públicas atinge 0.43 (em 2007 era de 0.16); ou seja, houve uma inversão - ampliação do número de matrículas em IES públicas e redução deste número em IES privadas.

3. No ano 2011, ao final do período analisado, há novamente uma proporção semelhante de matrículas nos dois setores. Todavia, ressalta-se que existem mais cursos de graduação em IES privadas do que em IES públicas. Segundo o censo da educação superior no ano 2010 (INEP, 2010), existem 284 (12\%) IES públicas e 2.081 (88\%) de privadas, num total de 2.365 instituições. Com relação à oferta de cursos de graduação, do total de 29.376, apenas 9.368 estão na rede pública, enquanto que 20.008 estão na rede privada. Esses dados permitem compreender que, embora a IES privada esteja em maior número, se a proporção de matrículas é semelhante ao quantitativo da IES pública, o número de matrículas de pessoas com deficiência é maior no setor público.

4. A criação do Programa Incluir gera nova mudança de comportamento do grupo, visto que, ao longo do último quinquênio, a quantidade de matrículas em IES públicas vem aumentando progressivamente. O Incluir começa em 2006, mas o impacto da criação desse programa é identificado em 2009, quando salta o número de matrículas de estudantes com deficiência em IES públicas. 
A reflexão instigada por esses dados é a de que, na década de 1990, boa parte dos estudantes com deficiência encontravam-se matriculados em instituições especializadas (privadas mantidas com recursos públicos), ocorrendo progressivamente a ampliação de matrículas na escola comum pública após a Declaração de Salamanca (UNESCO, 1994) e a Lei no 10.098 , de 19 de dezembro de 2000 (BRASIL, 2000).

No ensino superior brasileiro, a adequação dos espaços educacionais públicos passa a acontecer na medida em que os direitos das pessoas com deficiência são concretamente implementados por meio dos programas governamentais. No entanto, esse processo é de certo modo lento, visto que a cada ano se reconhecem avanços significativos, porém ainda insuficientes, se observados em paralelo aos dados do recenseamento populacional (IBGE, 2012). Em 2010, 6,7\% das pessoas com deficiência possuíam diploma de curso superior, enquanto $10,4 \%$ das pessoas sem deficiência o possuíam. Tais dados revelam que o acesso de pessoas com deficiência ainda é limitado, o que permite inferir que essa população é menos assistida que a população não deficiente.

\subsection{Condições de acessibilidade para estudantes com deficiência matriculados em cursos de graduação}

O resumo técnico publicado no ano 2010 apresenta desde a introdução uma explicação acerca da alteração no formato da coleta de dados e elementos requeridos às IES para atender à nova configuração apresentada pelo Programa Educação Inclusiva: Direito à diversidade e as tipologias de deficiências estabelecidas pela nova política de educação especial. A principal mudança foi a integração do Censo ao Cadastro e-MEC, cuja

[...] finalidade é permitir a interoperabilidade dos programas da educação superior, como: Programa Universidade para Todos (ProUni), Fundo de Financiamento ao Estudante do Ensino Superior (Fies), Exame Nacional de Desempenho de Estudantes (Enade), Sistema Nacional de Avaliação da Educação Superior (Sinaes), Sistema de Seleção Unificada (Sisu), Universidade Aberta do Brasil (UAB), etc. Em termos legais, o Cadastro e-MEC tornou-se o cadastro único de IES e de cursos por meio da Portaria Normativa $\mathrm{n}^{\mathrm{o}} 40$, de 12 de dezembro de 2007 (INEP, 2010, p. 20).

Essa modificação pode ser notada na apresentação geral dos dados e de modo específico com relação à pessoa com deficiência nas variáveis e categorizações da pesquisa de infraestrutura consideradas para o Censo 2010 - Condições de 
acessibilidade: rampas e vias acessíveis, mobiliário acessível, sanitário acessível, elevador acessível, sinalização visual, tátil e sonora. Todavia, o documento não apresenta tais dados - menciona que o censo não os coletou porque já constavam no e-MEC. Novamente, a única informação relacionada à pessoa com deficiência só aparece na variável alunos - ingresso - cotas ou reserva de vagas, porém não foi encontrado nenhum registro de reserva de vagas para pessoas com deficiência.

No Censo 2010, foram coletados dados sobre os tipos de deficiência: cegueira, baixa visão, surdez, deficiência auditiva, deficiência física, surdocegueira, deficiência múltipla, deficiência intelectual/mental e, no ano 2011, cegueira, visão subnormal ou baixa visão, deficiência intelectual e as novas tipologias: autismo infantil, Síndrome de Asperger, Síndrome de Rett, transtorno desintegrativo da infância e altas habilidades/superdotação.

No Censo 2011 foram criadas novas categorias na variável Recursos de Tecnologia Assistiva Disponíveis às Pessoas com Deficiência. $\mathrm{O}$ documento apresenta uma tabela em que faz alusão aos itens que se encontram presentes no Censo 2010: material em braille, material em áudio, sistema de síntese de voz, tradutor e intérprete de língua brasileira de sinais, guia-intérprete, material didático em língua brasileira de sinais, inserção da disciplina de língua brasileira de sinais no curso, material didático em formato impresso acessível e material didático digital acessível. No Censo 2011, foi excluído o item sistema de síntese de voz e acrescidos os itens: material pedagógico tátil, recursos de acessibilidade à comunicação, recursos de informática acessível e material em formato impresso em caráter ampliado. Identifica-se que, do total de 30.420 cursos de graduação declarados ao Censo 2011, 24.560 (80,7\%) ofertam condições de acessibilidade (condição para reconhecimento de cursos conforme Lei no 10.098/2000).

Em face dessa predominância de cursos com condições de acessibilidade disponíveis aos estudantes com deficiência, pode-se observar que há uma possível relação entre as demandas dos estudantes e a predominância do tipo de deficiência. No ano 2011, em meio a um total de 23.250 matrículas de estudantes com deficiência, três tipologias juntas somavam o equivalente a 89,58\% (20.851) do total - o que é possível relacionar aos recursos de acessibilidade disponibilizados pelas IES, como se pode notar no Quadro 2.

Os dados referentes às condições de acessibilidade permitem estabelecer uma conexão direta com o tipo de deficiência dos estudantes com o maior número de matrículas em IES. Foi possível evidenciar a predominância de matrículas de estudantes com deficiência física (DF), visual (DV) e auditiva (DA). A soma 
Quadro 2. Demandas dos estudantes com deficiência (2011).

\begin{tabular}{|c|c|c|c|}
\hline \multirow[t]{2}{*}{ Tipologia } & \multirow[t]{2}{*}{ Recursos para acessibilidade } & \multicolumn{2}{|c|}{$\begin{array}{l}\text { Quantidade de } \\
\text { estudantes }\end{array}$} \\
\hline & & N. & $\%$ \\
\hline \multirow[t]{5}{*}{ Deficiência física } & Rampas e vias acessíveis & \multirow[t]{5}{*}{5946} & \multirow[t]{5}{*}{25,57} \\
\hline & Mobiliário acessível & & \\
\hline & Sanitário acessível & & \\
\hline & Elevador acessível & & \\
\hline & Sinalização visual, tátil e sonora & & \\
\hline \multirow[t]{3}{*}{ Deficiência visual } & Material em Braille & \multirow[t]{3}{*}{9245} & \multirow[t]{3}{*}{39,76} \\
\hline & Material em áudio & & \\
\hline & Sistema de síntese de voz & & \\
\hline \multirow[t]{5}{*}{ Deficiência auditiva } & Guia-intérprete & \multirow[t]{5}{*}{5660} & \multirow[t]{5}{*}{24,34} \\
\hline & Material didático em língua brasileira de sinais & & \\
\hline & $\begin{array}{l}\text { Inserção da disciplina de língua brasileira de } \\
\text { sinais no curso }\end{array}$ & & \\
\hline & Material didático em formato impresso acessível & & \\
\hline & Material didático digital acessível & & \\
\hline
\end{tabular}

Fonte: Elaborado em março de 2014 pelas autoras com dados de INEP (2012).

do número de matrículas dessas três deficiências representa $89,68 \%$ do total de matrículas de PcD do ano 2011.

Em comparação com as demais deficiências, a visual (inclui baixa visão e cegueira) representa $39,76 \%$ das matrículas, seguida da deficiência física $25,57 \%$ e da deficiência auditiva (inclui surdez) com 24,34\% (Figura 2).

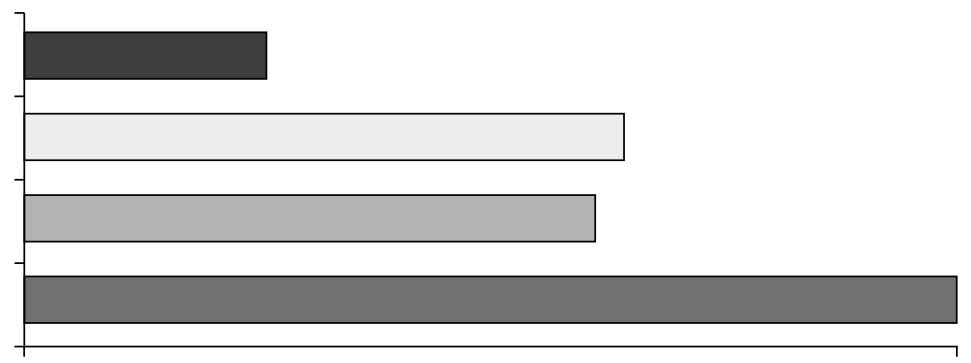

Fonte: INEP (2011).

Elaborado em março/2014.

Figura 2. Maior índice de matrículas por tipo de deficiência (2011). 
As outras deficiências representam apenas $10,32 \%$ das matrículas e não são mencionados os elementos que viabilizam a acessibilidade para essas pessoas (Tabela 2).

Tabela 2. Maior índice de matrículas por tipo de deficiência.

\begin{tabular}{lccccccccc}
\hline Ano & Total & $\begin{array}{c}\text { DV, DA e } \\
\text { DF Fa (N) }\end{array}$ & $\begin{array}{c}\text { DV, DA e } \\
\text { DF (\%) }\end{array}$ & DV & $\begin{array}{c}\text { DV FR } \\
\text { (\%) }\end{array}$ & DA & $\begin{array}{c}\text { DA FR } \\
\text { (\%) }\end{array}$ & DF & DF (\%) \\
\hline 2000 & 2.173 & 1.462 & 67,28 & 335 & 15,42 & 347 & 15,97 & 780 & 35,90 \\
2001 & 2.898 & 1.573 & 54,28 & 413 & 14,25 & 244 & 8,42 & 916 & 31,61 \\
2002 & 2.425 & 2.003 & 82,60 & 607 & 25,03 & 344 & 14,19 & 1.052 & 43,38 \\
2003 & 5.078 & 2.972 & 58,53 & 920 & 18,12 & 665 & 13,10 & 1.387 & 27,31 \\
2004 & 5.395 & 4.346 & 80,56 & 1.665 & 30,86 & 975 & 18,07 & 1.706 & 31,62 \\
2005 & 6.327 & 5.041 & 79,67 & 1.756 & 27,75 & 1.245 & 19,68 & 2.040 & 32,24 \\
2006 & 6.960 & 5.613 & 80,65 & 1.980 & 28,45 & 1.400 & 20,11 & 2.233 & 32,08 \\
2007 & 6.934 & 5.887 & 84,90 & 1.966 & 28,35 & 1.446 & 20,85 & 2.475 & 35,69 \\
2008 & 12.015 & 10.937 & 91,03 & 5.286 & 44,00 & 2.124 & 17,68 & 3.527 & 29,35 \\
2009 & 20.965 & 19.854 & 94,70 & 8.930 & 42,59 & 6.542 & 31,20 & 4.382 & 20,90 \\
2010 & 20.287 & 19.206 & 94,67 & 8.779 & 43,27 & 4.693 & 23,13 & 5.734 & 28,26 \\
2011 & 23.250 & 20.851 & 89,68 & 9.245 & 39,76 & 5.660 & 24,34 & 5.946 & 25,57 \\
\hline
\end{tabular}

Fonte: Elaborado em março de 2014 pelas autoras com dados obtidos pela leitura dos indicadores educacionais do INEP referente ao período 2000-2011.

Ao longo da série histórica, nota-se que o número de matrículas de estudantes com deficiência visual, auditiva e física amplia-se. No entanto, destaca-se que pessoas com deficiência visual vêm superando as barreiras de acesso ao ensino superior em maior número. Os dados acima apresentados revelam que o acesso desses estudantes é condicionado ainda pelo tipo de deficiência. Até 2006, a nomenclatura deficiência visual (DV) abarcava cegueira e baixa visão; a partir desse ano foram criadas tipologias específicas para uma e outra deficiência. $\mathrm{O}$ termo surdez passou a ser empregado para nomear parte da categoria deficiência auditiva a partir de 2007.

O quantitativo equivalente a cada tipo de deficiência foi sistematizado de modo a permitir melhor apresentação dos dados, sendo inseridos juntamente deficiência visual/cegueira /baixa visão e surdez/deficiência auditiva. A apresentação desses dados tem por objetivo refletir sobre a propagação da acessibilidade adequada para cada tipo de deficiência evitando acepção generalizada, o que tende a favorecer a participação qualitativa dos sujeitos em face de suas características individuais. 
Para além de uma visão superficial, esta pesquisa se esforça por olhar para as condições de acessibilidade específicas para cada tipo de deficiência.

Para pessoas com baixa visão, por exemplo, são disponibilizados material em braille, áudio, sistema de síntese de voz, material didático em formato impresso e digital acessível, material pedagógico tátil, recursos de acessibilidade à comunicação, recursos de informática acessível e material em formato impresso em caráter ampliado.

Com relação aos recursos de acessibilidade acima citados, nota-se maior uso de recursos para transposição de barreiras comunicacionais do que para as arquitetônicas (rampas e vias acessíveis, mobiliário acessível e sanitário acessível). A atuação do intérprete de língua de sinais, guia-intérprete, a sinalização visual, tátil e sonora, a produção de material em Braille e áudio, a inserção da disciplina língua brasileira de sinais e a elaboração do material didático nessa mesma língua remetem à necessidade de transpor barreiras que emergem da necessidade comunicativa, muitas vezes, num contexto propriamente educacional.

\section{Considerações finais}

As políticas públicas para o acesso de pessoas com deficiência ao ensino superior brasileiro vêm sofrendo ao longo dos últimos dez anos um processo de adequação ao pleito mundial. Os organismos internacionais, tais como a Organização das Nações Unidas para a Educação, a Ciência e a Cultura (Unesco), suscitam a ampliação do investimento em educação, no sentido de favorecer o acesso de grupos socialmente desfavorecidos ao ensino público.

Nessa perspectiva, o ensino destinado às pessoas com deficiência tem se inserido no rol de prioridades governamentais instigando a adequação dos recursos educacionais e a transposição de barreiras. A análise dos dados permite identificar a evolução do número de matrículas de estudantes com deficiência em cursos de graduação presencial e a distância, sobretudo em instituições públicas após a criação do Programa Incluir. De modo geral, o quadro de matrículas de pessoas com deficiência no ensino superior evolui em termos numéricos, mas ainda representa uma camada mínima da população com deficiência efetivamente matriculada nessa etapa da escolarização.

No que tange à IES pública, a matrícula vem se ampliando, uma possível consequência da implementação de programas do governo federal, oriundos pontualmente da gestão petista iniciada no ano 2003. Tal modo de gestão do 
serviço público tem impactado a organização da educação nacional e, de modo específico, o formato da Educação Especial cujos projetos e operacionalização assumem por base o atendimento educacional especializado, que, na educação básica, tem como lócus prioritário a Sala de Recursos Multifuncionais e, na educação superior, o Programa Incluir - pela criação dos núcleos de acessibilidade.

No entanto, é necessário ainda investigar criticamente as causas da presença inexpressiva de estudantes com deficiência no ensino superior quando se comparado aos números de matrículas na educação fundamental. Por fim, percebe-se que o acesso, a permanência e a conclusão de cursos por parte de estudantes com deficiência no ensino superior brasileiro ainda carece de estudos, visando a transposição de barreiras atitudinais, metodológicas, programáticas e/ou instrumentais, além de investimentos na formação de recursos humanos no atendimento as necessidades educacionais especiais por vezes apresentadas por esses estudantes. 


\title{
Public policy for disabled persons' access to higher education in Brazil: an analysis of educational indicators
}

\begin{abstract}
This study sought to analyze the enrollment policies for special education in Brazilian higher education programs derived from educational indicators. The study is characterized as analytic-descriptive and was based on primary sources; they included technical reports and data from the Brazilian Higher Education Census Bureau from 2000 to 2011, as well as documents from the country's accessibility program known as Include (Incluir, in original Portuguese) from 2005 to 2011. The decade in question was selected in line with understanding the federal government's measures planned in the country's National Education Plan, which were focused on increasing enrollment in Brazilian higher education programs. The need to question the results of the aforementioned measures also justified the choice of the period to be studied. The data analysis revealed an increase in the number of disabled students enrolled in traditional and online undergraduate degree programs (particularly at Brazilian public universities) following the initiation of the Include Program. Overall, enrollments among disabled students in higher education programs increased in terms of numbers; however, the percentage still represents only a small part of the disabled population.
\end{abstract}

Keywords: Higher education. Special education. Educational indicators.

\section{Políticas públicas para el acceso de personas con deficiencia en la educación superior brasileña: un análisis de indicadores educativos}

\section{Resumen}

El objetivo del trabajo es analizar las políticas relacionadas con la matrícula de la educación especial en la educación superior brasileña con base en indicadores educativos. La investigación es descriptiva-analítica de base documental, cuyas fuentes de datos son resúmenes técnicos y planillas del Censo de la Educación Superior en el periodo del 2000 al 2011 y, documentos del Programa Incluir del periodo del 2005 al 2011, quinquenio en que fue implantado. La selección de la década en cuestión se justifica por las acciones del gobierno federal previstas en el Plan Nacional de Educación, dirigidas a la ampliación de la matrícula en la educación superior brasileña y por la necesidad de estimar los resultados de esas acciones. El análisis de datos permite identificar la evolución del número de estudiantes con discapacidad matriculados en los cursos de pregrado presenciales y a distancia, y sobre todo, en instituciones públicas, después de la creación del Programa Incluir. En general, la matrícula de personas con discapacidad en la educación superior evolucionó en términos numéricos, sin embargo, constituye un porcentaje mínimo de la población con deficiencia efectivamente matriculada en esa etapa de la escolarización.

Palabras clave: Educación superior. Educación especial. Indicadores educativos. 


\section{Referências}

BRASIL. Decreto legislativo no 186 , de 2008. Aprova o texto da convenção sobre os direitos das pessoas com deficiência e de seu protocolo facultativo assinados em Nova Iorque em 30 de março de 2007. Brasília, DF, 2008a. Disponível em $<$ http://www.planalto.gov.br/ccivil_03/constituicao/congresso/ DLG/DLG-186-2008.htm>. Acesso em 10 ago. 2013.

. Decreto $\mathrm{n}^{\mathrm{0}} 5.209$, de 17 de setembro de 2004. Regulamenta a lei $\mathrm{n}^{\circ}$ 10.836, de 9 de janeiro de 2004, que cria o Programa Bolsa Família, e dá outras providências. Diário Oficial da União, Brasília, DF. 20 set. 2004a.

. Decreto $\mathrm{n}^{\circ} 5.296$, de 2 de dezembro de 2004. Estabelece normas gerais e critérios básicos para a promoção da acessibilidade das pessoas portadoras de deficiência ou com mobilidade reduzida, e dá outras providências. Diário Oficial da União, Brasília, DF, 3 dez. 2004b.

. Decreto $\mathrm{n}^{\mathrm{0}}$ 6.571, de 17 de setembro de 2008. Dispõe sobre o atendimento educacional especializado, regulamenta o parágrafo único do art. 60 da Lei no 9.394, de 20 de dezembro de 1996, e acrescenta dispositivo ao Decreto $\mathrm{n}^{\mathrm{o}} 6.253$, de 13 de novembro de 2007. Diário Oficial da União, Brasília, DF, 18 set. 2008 b.

. Decreto $\mathrm{n}^{\mathrm{0}} 7.611$, de 17 de novembro de 2011. D ispõe sobre a educação especial, o atendimento educacional especializado e dá outras providências. Diário Oficial da União, Brasília, DF, 18 nov. 2011a.

. Decreto $n^{0} 72.425$, de 1973. Cria o Centro nacional de Educação Especial (CENESP), e dá outras providências. Diário Oficial União, seção 1, p. 6426, 4 jul. 1973.

. Lei n. 9.394, de 20 de dezembro de 1996. Estabelece as Diretrizes e Bases da Educação Nacional. Diário Oficial da União, Brasília, DF, 23 dez. 1996a.

. Lei $\mathrm{n}^{\mathrm{0}} 10.098$, de 19 de dezembro de 2000. Estabelece normas gerais e critérios básicos para a promoção da acessibilidade das pessoas portadoras de deficiência ou com mobilidade reduzida, e dá outras providências. Diário Oficial da União, Brasília, DF, 20 dez. 2000.

. Ministério da Educação. Conselho Nacional de Educação. Câmara de Educação Básica. Resolução no 4, de 2 de outubro de 2009. Institui diretrizes operacionais para $\mathrm{o}$ atendimento educacional especializado na educação básica, modalidade educação especial. Brasília, DF, 2009. Disponível em <http://portal. mec.gov.br/dmdocuments/rceb004_09.pdf $>$. Acesso em: 10 ago. 2013. 
BRASIL. Ministério da Educação. Lei n ${ }^{\circ}$ 10.172, de 9 de janeiro de 2001. Aprova o Plano Nacional de Educação e dá outras providências. Diário Oficial da União, Brasília, DF, 10 jan. 2001.

. Ministério da Educação. Secretaria de Educação Especial. Política Nacional de Educação Especial. Brasília, DF, 2008c.

. Ministério da Educação. Secretaria de Educação Especial. Evolução da educação especial no Brasil. Brasília, DF, 2006a.

. Ministério da Educação. Secretaria de Educação Especial. Diretrizes nacionais para a educação especial na educação básica. Brasília, DF, 2001. . Ministério da Educação. Secretaria de Educação Especial. Nota Técnica SEESP/GAB/No 8/2011, sobre Orientação para promoção de acessibilidade nos exames nacionais. Brasília, DF, 2011.

. Presidência da República. Aviso Circular nº 277. Brasília, DF, 8 maio 1996 b.

. Presidência da República. Brasil 2003 a 2010. Brasília, DF, 2013.

. Secretaria de Educação Especial. Portaria $n^{0} 3.284$, de 7 de novembro de 2003. Dispõe sobre requisitos de acessibilidade de pessoas portadoras de deficiências, para instruir os processos de autorização e de reconhecimento de cursos, e de credenciamento de instituições. Diário Oficial da União, Brasília, DF, 11 nov. 2003.

. Secretaria de Educação Superior. Edital $n^{\circ} 2$. Programa Incluir. Diário Oficial da União, Brasília, DF, seção 3, p. 39-40, 17 maio 2005.

BUENO, J. G. S.; MELETTI, S. Educação infantil e educação especial: uma análise dos indicadores educacionais brasileiros. ContraPonto, Belo Horizonte, v. 11, n. 3, p. 278-87, dez. 2011. doi:10.14210/contrapontos.v11n3.p278-287

CADERNO temático do programa de governo: Uma escola do tamanho do Brasil. São Paulo: Coligação Lula Presidente, 2002.

GARCIA, R. M. C.; MICHELS, M. H. A política de educação especial no Brasil (1991-2011): uma análise da produção do GT15 Educação Especial da Anped. Revista Brasileira de Educação Especial, v. 17, n. esp., p. 105-24, maio-ago. 2011. doi:10.1590/S1413-65382011000400009 
GENTILI, P. Neoliberalismo e educação: manual do usuário. In: SILVA, T. T.; GENTILI, P. (Org.). Escola S.A: quem ganha e quem perde no mercado educacional do neoliberalismo. Brasília, DF: CNTE, 1996. p. 9-49.

INSTITUTO NACIONAL DE ESTUDOS E PESQUISAS EDUCACIONAIS ANÍSIO TEIXEIRA - INEP. Censo da educação superior 2003 : resumo técnico. Brasília, DF, 2003.

. Censo da educação superior 2009: resumo técnico. Brasília, DF, 2009. . Censo da educação superior 2010. Brasília, DF, 2010.

. Censo da educação superior 2010: resumo técnico. Brasília, DF, 2012. . Censo da educação superior 2011. Brasília, DF, 2011.

. Censo da educação superior 2011: resumo técnico. Brasília, DF, 2013. . Pesquisa Nacional por Amostra de Domicílios. Rio de Janeiro: 2012.

JANUZZI, G. S. M. A educação do deficiente no Brasil: dos primórdios ao início do século XXI.. Campinas: Editora Autores Associados, 2004. (Coleção Educação Contemporânea).

KASSAR, M. C. M. Deficiência múltipla e educação no Brasil: discurso e silêncio na história de sujeitos. Campinas, SP: Autores Associados, 1999.

. Liberalismo, neoliberalismo e educação especial: algumas implicações. Cadernos CEDES, Campinas, v. 19, n. 46, p. 16-28, set. 1998. doi:10.1590/S0101-32621998000300003

MAZZOTTA, Marcos José Silveira. Educação especial no Brasil: história e políticas públicas. São Paulo: Cortez, 2001.

NORONHA, O. M. Politicas neoliberais, conhecimento e educação. 2. ed. Campinas: Alínea, 2002.

OLIVEIRA, D. A. As políticas educacionais no governo Lula: rupturas e permanências. Revista Brasileira de Política e Administração da Educação, v. 25, p. 197-210, 2009.

ORGANIZAÇÃO DAS NAÇÕES UNIDAS PARA A EDUCAÇÃO, CIÊNCIA E CULTURA - UNESCO. Declaração de Salamanca e linha de ação sobre necessidades educativas especiais. Salamanca, 1994. 
ORGANIZAÇÃO DAS NAÇÕES UNIDAS PARA A EDUCAÇÃO, CIÊNCIA E CULTURA - UNESCO. Declaração mundial sobre educação para todos (Conferência de Jomtien). Tailândia, 1990.

SINGER, A. V. Os sentidos do lulismo: reforma gradual e pacto conservador. São Paulo: Companhia das Letras, 2012.

\section{Informações das autoras}

Diléia Aparecida Martins: Doutoranda em Educação Especial, Universidade Federal de São Carlos - UFSCar. Bolsista - CAPES, pelo programa Observatório em Educação (OBEDUC), Projeto Acessibilidade no Ensino Superior. Brasil. Contato: dileiamartins@gmail.com

Lúcia Pereira Leite: Doutorado em Educação pela, Universidade Estadual Paulista/Campus Marília - Unesp/Marília. Professora do Departamento de Psicologia e do Programa de Pós-graduação em Psicologia do Desenvolvimento e Aprendizagem, Universidade Estadual Paulista/Campus Bauru - Unesp/Bauru. Brasil. Contato: lucialeite@fc.unesp.br

Cristina Broglia Feitosa de Lacerda: Doutorado em Educação, Universidade Estadual de Campinas - Unicamp. Coordenadora , Programa de Pós Graduação em Educação Especial/Universidade Federal de São Carlos - PPGEEs/UFSCar. Docente do curso de licenciatura em Educação Especial, Universidade Federal de São Carlos - UFSCar, Grupo de Pesquisa Abordagem Bilíngue e Surdez. Brasil. Contato: clacerda@ufscar.br; cristinalacerda@uol.com.br 